\title{
Moral Disengagement and Classroom Incivility against the Social Responsibility Character of Junior High School Students
}

\author{
Susilawati ${ }^{1}$, Mungin Eddy Wibowo, and Sunawan \\ Universitas Bengkulu, Indonesia ${ }^{1}$ \\ Universitas Negeri Semarang, Indonesia \\ هusilawatisusan028@gmail.com ${ }^{1}$
}

Article Information:

Received December 16, 2019

Revised December 17, 2019

Accepted December 20, 2019

Keywords: incivility classroom; moral disengagement; social responsibility

\section{Abstract}

Nowadays social responsibility is significant to investigate. It is because in the academic world there are a number of students having low social responsibility. This behavior is realized by unfair actions in groups, bullying or intimidation practice. Concerning this phenomenon, the current study aimed at analyzing the prediction of students' social responsibility from the perspective of moral disengagement and incivility. This correlational study involved 636 students with a portion of $49.5 \%$ of male students and $50.5 \%$ of female students. They were selected using cluster sampling from two junior high schools in Central Java. After that, these students were asked to fill in a moral disengagement scale, and classroom incivility scale. The results showed that moral disengagement and incivility significantly predicted social responsibility $(R=0.336, R 2=0.113, F=6.079$, and $P<0.01)$. Specifically, the findings of this study confirmed that the aspects of Moral Justification and Dehumanization, as well as intentional incivility, predict students' social responsibility.

\section{INTRODUCTION}

Humans are social beings. That is why they need to have the character of responsibility in social life. Many factors are influencing the level of one's social responsibility, such as empathy, moral development, and self-concepts that develop since childhood and adolescence (Wray-Lake \& Syvertsen, 2011). School is a place to teach responsibility to students. Students who are socially responsible tend to have a greater concern for ethical and moral issues (Gough, McClosky, \& Meehl, 1952).

People who act maturely and socially responsible have a strength of character in citizenship, a higher level of social trust, and a more positive view of human nature (Peterson \& Seligman, 2004). Concerning this, social responsibility is related to morality. The theory of moral reasoning indicates that social responsibility attitudes are derived from justice-based moral reasoning (Kohlberg, 1969). Meanwhile, the social-cognitive theory states that morality refers to the concept of human well-being, justice, and respect for human rights as forms of maintaining personal relationships (Nucci, 2001).

Previous studies revealed that those who have high moral sensitivity are children who are against moral disengagement and oppose immoral acts, for example, intimidation against humans. It is also known that moral disengagement is positively related to aggression (Bandura, Barbaranelli, Caprara, \& Pastorelli, 1996; Bandura, Caprara, Barbaranelli, Pastorelli, \& Regalia, 2001; Barchia \& Bussey, 2011; Paciello, Fida, Tramontano, Lupinetti, \& Caprara,

\section{How to cite: \\ E-ISSN:}

Published by:
Susilawati, S., Wibowo, M., \& Sunawan, S. (2019). Moral Disengagement and Classroom Incivility against the Social Responsibility Character of Junior High School Students. Islamic Guidance and Counseling Journal, 3(1). https://doi.org/10.25217/igcj.v3i1.661 2614-1566

Institut Agama Islam Ma'arif NU (IAIMNU) Metro Lampung 
2008; Pelton, Gound, Forehand, \& Brody, 2004; Pornari \& Wood, 2010; White-Ajmani \& Bursik, 2014), including bullying behavior toward others (Gini, Pozzoli, \& Hauser, 2011; Hymel, Rocke-Henderson, \& Bonanno, 2005; Menesini et al., 2003; Obermann, 2011; Perren, Gutzwiller-Helfenfinger, Malti, \& Hymel, 2012), and antisocial behavior (Bandura et al., 1996, 2001; Hyde, Shaw, \& Moilanen, 2010). Besides, intimidating others is also a form of social irresponsibility and moral disengagement.

Incivility is an errant behavior that is disruptive and even harmful so that it may cause the learning atmosphere disharmonious (Andersson \& Pearson, 1999; Boysen, 2012; Knepp, 2012; Miller, Katt, Brown, \& Sivo, 2014). This kind of behavior has various levels, starting from not listening to the discussion, lack of attention to the class, lateness, absence, having a chat with friends when teacher is explaining materials, sleeping in class, saying dirty words, having a physical or verbal contact against teachers or other students (Alberts, Hazen, \& Theobald, 2010). Other forms of this behavior are such as intimidating peers, harassment, and threatening friends and teachers (Burke, Karl, Peluchette, \& Evans, 2014; Feldmann, 2001). Thus, performing classroom incivility is a form of misconduct that affects one's social responsibility.

If the previous studies discussed the relationship between responsibility and moral disengagement, the current study aimed at examining which moral disengagement and incivility aspects influenced the relationship with students' social responsibility. These were done because responsibility is a significant thing in human life aspects, particularly in social life. Moreover, the authors were also interested in knowing whether there was a relationship between responsibility, moral disengagement, and classroom incivility seen from the influencing aspects. These matters were used as the basis for determining the next intervention.

\section{METHODS}

This study belonged to a correlational study and involved 3 variables, namely responsibility, moral disengagement, and classroom incivility. For more, the respondents of this study were selected using cluster sampling from two junior high schools in Semarang City and Temanggung Regency. 636 students were covering 321 female students, and 315 male students from the seventh and eighth grades.

The data collection was carried out using three instruments. First, the instrument used to collect the data of responsibility variable was an academic integrity scale designed by Ramdani (2018) containing 10 statement items. The validity of this scale was measured based on a correlation 0.00 and the reliability 0.769 . The scale was rated using the Likert scale in which the statement items were favorable and contained 5 answer choices $(1=$ strongly disagree to $5=$ strongly agree).

Second, moral disengagement was measured using moral disengagement scale developed by Bandura et al., (1996) containing 32 statement items with the validity is 0.00 and reliability is 0.786 . This instrument was rated using the Likert scale in which the statement items were unfavorable, and available with 4 answer choices ( $1=$ strongly disagree to $5=$ strongly agree).

Third, classroom incivility was rated by classroom incivility scale developed by Farrell, Provenzano, Spadafora, Marini, \& Volk (2016). This instrument was rated using the Likert scale in which the statement items were favorable, and available with 5 answer choices ( $1=$ strongly disagree to $5=$ strongly agree). The validity of this instrument ranged from 0.02 to 0.01 while its reliability was at 0.813 .

To collect the data, the authors conducted several procedures, namely managing the administrative permission to research the designated schools, determining classes to be used as the sample, and distributing the scales to be filled in by the students. After the scales were submitted, they were analyzed by using a hierarchical regression test to find out the relationship between moral disengagement, incivility classroom, students' social responsibility character controlled by gender, class, and age. 


\section{RESULTS AND DISCUSSION}

This study found out that there was a relationship between social responsibility, moral disengagement, and classroom incivility when the demography variable acted as a control. It was proved by the results of hierarchical regression test showing that social responsibility had a relationship with moral disengagement with the value of $\Delta \mathrm{R}=0.078$, while the aspect of moral disengagement variable which predicted the existence of the relationship was moral justification with the value of $\beta=0.095, t=2.105$, and $\mathrm{P}<0.05$. Another aspect that predicted the relationship between responsibility and moral disengagement was the dehumanization aspect with the value of $\beta=-.099, \mathrm{t}=-2,309$ and $\mathrm{P}<0.05$. Additionally, classroom incivility was also found to influence responsibility variable with the value of delta $R=0.048$, while the aspect which predicted the relationship between classroom incivility and responsibility was intentional incivility aspect with the value of $\beta=-.165, \mathrm{t}=-3,570$ and $\mathrm{P}<0.01$. If it is thoroughly seen, moral disengagement and classroom incivility were related to responsibility by having $\mathrm{R}=0.336$, $\mathrm{R}^{2}=0.113, \mathrm{~F}=6,079$, and $\mathrm{P}<0.01$. The details of these findings can be seen in the following Table 1 .

\begin{tabular}{|c|c|c|c|c|c|c|c|c|}
\hline \multirow{2}{*}{ Pre- Indicators } & \multicolumn{3}{|c|}{ Model 1} & \multicolumn{3}{|c|}{ Model 2} & \multicolumn{2}{|c|}{ Model 3} \\
\hline & $\beta$ & $\mathrm{t}$ & $\mathrm{P}$ & $\beta$ & $\mathrm{T}$ & $\mathrm{P}$ & $\beta$ & $\mathrm{P}$ \\
\hline Class & .157 & 3.535 & .000 & .125 & 2.779 & .006 & .143 & 3.147 .002 \\
\hline Gender & -.140 & -3.575 & .000 & -.137 & -3.320 & .001 & -.128 & -3.154 .002 \\
\hline Age & -.035 & -.799 & .425 & -.012 & -.272 & .786 & -.019 & -.438 .661 \\
\hline \multicolumn{9}{|l|}{ Moral Disengagement } \\
\hline Moral Justification & & & & .074 & 1.622 & .105 & .095 & 2.105 .036 \\
\hline Euphemistic Labeling & & & & -.119 & -2.543 & .011 & -.075 & -1.581 .114 \\
\hline Advantageous Comparison & & & & -.043 & -.924 & .356 & -.042 & -.925 .355 \\
\hline Displacement Of Responsibility & & & & .024 & .512 & 609 & .030 & .651 .516 \\
\hline Diffusion Of Responsibility & & & & .059 & 1.311 & .190 & .060 & 1.364 .173 \\
\hline Distortion Of Consequences & & & & 0.00 & -.010 & .992 & .017 & 690 \\
\hline Attribution Of Blame & & & & -.004 & -.080 & .936 & .006 & $.147 \quad .883$ \\
\hline Dehumanization & & & & -.128 & -2.968 & .003 & -.099 & -2.309 .021 \\
\hline \multicolumn{9}{|l|}{ Incivility Classroom } \\
\hline Unintentional Incivility & & & & & & & -.052 & -1.126 .260 \\
\hline Intentional Incivility & & & & & & & -.165 & -3.5700 .00 \\
\hline$\overline{\Delta \mathrm{R}}$ & & & & & 0.078 & & & 0.048 \\
\hline$\Delta \mathrm{R} 2$ & & & & & 0.039 & & & 0.030 \\
\hline$\Delta \mathrm{P}$ & & & & & 0.01 & & & 0.00 \\
\hline$\overline{\mathrm{R}}$ & & .210 & & & 0.288 & & & .336 \\
\hline R2 & & .044 & & & 0.083 & & & .113 \\
\hline $\mathrm{F}$ & & 9.759 & & & 5.125 & & & 6.079 \\
\hline $\mathrm{P}$ & & 0.00 & & & 0.00 & & & 0.00 \\
\hline
\end{tabular}

Table 1. The Results of Hierarchical Correlational Test

This study investigate the aspects of moral disengagement and classroom incivility which negatively predicted students' social responsibility. The findings confirmed that both moral disengagement and classroom incivility negatively predicted students' social responsibility. Based on theories, intimidation is the realization of low social responsibility (Gini et al., 2011). Therefore, it can be concluded that people whose social responsibility is high tend to concern about justice and care (Peterson \& Seligman, 2004). Meanwhile, classroom incivility can be in the form of intimidating friends, harassment, and threatening both friends and teachers (Burke et al., 2014). Intimidation is a manifestation of low social responsibility and has a relationship 
with moral disengagement and classroom incivility. Interestingly, the study successfully confirmed that the aspects of moral disengagement which negatively predicted social responsibility were moral justification and dehumanization. Meanwhile, in terms of classroom incivility, the aspect which influenced this negative behavior was intentional incivility.

In this study, the aspects of moral disengagement which negatively predicted social responsibility were moral justification and dehumanization. In moral justification, students who had no social responsibility were those who considered an amoral action such as intimidating people is not a mistake. Meanwhile, the aspect of dehumanization was realized by students who did not practice social responsibility well or students who experienced a decline in social responsibility values. These findings strengthen the previous study results that the Diffusion of Responsibility significantly predicts intimidation practice by behaving unfairly in a group environment (Robson \& Witenberg, 2013). Further, the influencing aspect of classroom incivility was intentional incivility. It was realized by students' intention in performing incivility, in this case, is intimidating others. Miller et al. (2014) revealed that students' incivility appears in some form of negative behaviors, such as disrupting the learning process and messing up classroom conduciveness.

The findings of this study are also in line with Knepp's (2012) that incivility is related to amoral behaviors by students, such as rejecting teacher's orders and ignoring rules, and moral disengagement which jointly influence students' characters, especially social responsibility. Therefore, in this study intimidating others were understood as an amoral act and bad social responsibility. As a result, students who intentionally intimidate others and consider their act not amoral can be said to have a bad social responsibility for the social environment.

Apart from its findings, this study had a limitation. The limitation was in the form of the limited data derived from two areas in Central Java, namely Semarang and Temanggung Regency. The researchers considered that these data did not represent the whole area in Central Java. Thus, future researchers should consider the areas of data collection, and apply classical guidance services to improve students' responsibility and decrease moral disengagement as well as classroom incivility.

\section{CONCLUSIONS}

The findings of this study confirm that moral disengagement and incivility negatively predict students' social responsibility characters. The relationship between these two variables on social responsibility is negative, meaning that the higher level of moral disengagement and incivility owned by students would result in the lower social responsibility character. For more, moral justification and dehumanization in moral disengagement, and intentional incivility in classroom incivility are aspects which influence negative social responsibility. They further disrupt the learning process, and trigger students to intimidate class members. Even though this study has successfully explained the relationship between moral disengagement, incivility and social responsibility, there were some limitations found. First, the moral disengagement, incivility, and social responsibility in this study were examined correlatively. Also, this study was carried out only in junior high school level. Therefore, future studies are expected to employ a longitudinal study by using latent group modeling analysis or experimental design to reduce intimidating behavior either intentionally or unintentionally.

\section{ACKNOWLEDGMENTS}

The authors would like to thank Universitas Negeri Semarang and the Ministry of Research, Technology, and Higher Education which has funded this study based on the contracts number 078/SP2H/LT/DPRM/2019 and 33.18.3/UN37/PPK.3.1/2019. 


\section{AUTHOR CONTRIBUTION STATEMENTS}

The authors had participated in the research and approved the final manuscript.

\section{REFERENCES}

Alberts, H. C., Hazen, H. D., \& Theobald, R. B. (2010). Classroom Incivilities: The Challenge of Interactions between College Students and Instructors in the US. Journal of Geography in Higher Education, 34(3), 439-462. https://doi.org/10.1080/03098260903502679

Andersson, L. M., \& Pearson, C. M. (1999). Tit for Tat? The Spiraling Effect of Incivility in the Workplace. Academy of Management Review, 24(3), 452-471. https://doi.org/10.5465/amr.1999.2202131

Bandura, A., Barbaranelli, C., Caprara, G. V., \& Pastorelli, C. (1996). Mechanisms of moral disengagement in the exercise of moral agency. Journal of Personality and Social Psychology, 71(2), 364-374. https://doi.org/10.1037//0022-3514.71.2.364

Bandura, A., Caprara, G. V., Barbaranelli, C., Pastorelli, C., \& Regalia, C. (2001). Sociocognitive self-regulatory mechanisms governing transgressive behavior. Journal of Personality and Social Psychology, 80(1), 125-135. https://doi.org/10.1037/00223514.80.1.125

Barchia, K., \& Bussey, K. (2011). Individual and collective social cognitive influences on peer aggression: Exploring the contribution of aggression efficacy, moral disengagement, and collective efficacy. Aggressive Behavior, 37(2), 107-120. https://doi.org/10.1002/ab.20375

Boysen, G. A. (2012). Teacher Responses to Classroom Incivility: Student Perceptions of Effectiveness. Teaching of Psychology, 39(4), 276-279. https://doi.org/10.1177/0098628312456626

Burke, L. A., Karl, K., Peluchette, J., \& Evans, W. R. (2014). Student Incivility: A Domain Review. Journal of Management Education, 38(2), 160-191. https://doi.org/10.1177/1052562913488112

Farrell, A. H., Provenzano, D. A., Spadafora, N., Marini, Z. A., \& Volk, A. A. (2016). Measuring Adolescent Attitudes Toward Classroom Incivility: Exploring Differences Between Intentional and Unintentional Incivility. Journal of Psychoeducational Assessment, 34(6), 577-588. https://doi.org/10.1177/0734282915623446

Feldmann, L. J. (2001). Classroom Civility is Another of Our Instructor Responsibilities. College Teaching, 49(4), 137-140. https://doi.org/10.1080/87567555.2001.10844595

Gini, G., Pozzoli, T., \& Hauser, M. (2011). Bullies have enhanced moral competence to judge relative to victims, but lack moral compassion. Personality and Individual Differences, 50(5), 603-608. https://doi.org/10.1016/j.paid.2010.12.002

Gough, H. G., McClosky, H., \& Meehl, P. E. (1952). A personality scale for social responsibility. The Journal of Abnormal and Social Psychology, 47(1), 73-80. https://doi.org/10.1037/h0062924

Hyde, L. W., Shaw, D. S., \& Moilanen, K. L. (2010). Developmental Precursors of Moral Disengagement and the Role of Moral Disengagement in the Development of Antisocial Behavior. Journal of Abnormal Child Psychology, 38(2), 197-209. https://doi.org/10.1007/s10802-009-9358-5

Hymel, S., Rocke-Henderson, N., \& Bonanno, R. A. (2005). Moral disengagement: A framework for understanding bullying among adolescents. Journal of Social Sciences, 8(1), 1-11. Retrieved from Google Scholar

Knepp, K. A. F. (2012). Understanding Student and Faculty Incivility in Higher Education. Journal of Effective Teaching, 12(1), 33-46. https://eric.ed.gov/?id=EJ1092106 
Kohlberg, L. (1969). Stage and Sequence: The Cognitive-Development Approach to Socialization. In Handbook of Socialization Theory and Research (pp. 348-380). Retrieved from Google Scholar

Menesini, E., Sanchez, V., Fonzi, A., Ortega, R., Costabile, A., \& Lo Feudo, G. (2003). Moral emotions and bullying: A cross-national comparison of differences between bullies, victims and outsiders. Aggressive Behavior, 29(6), 515-530. https://doi.org/10.1002/ab.10060

Miller, A. N., Katt, J. A., Brown, T., \& Sivo, S. A. (2014). The Relationship of Instructor SelfDisclosure, Nonverbal Immediacy, and Credibility to Student Incivility in the College Classroom. Communication Education, 63(1), 1-16. https://doi.org/10.1080/03634523.2013.835054

Nucci, L. P. (2001). Education in the Moral Domain. Retrieved from Google Scholar

Obermann, M.-L. (2011). Moral Disengagement Among Bystanders to School Bullying. Journal of School Violence, 10(3), 239-257. https://doi.org/10.1080/15388220.2011.578276

Paciello, M., Fida, R., Tramontano, C., Lupinetti, C., \& Caprara, G. V. (2008). Stability and Change of Moral Disengagement and Its Impact on Aggression and Violence in Late Adolescence. Child Development, 79(5), 1288-1309. https://doi.org/10.1111/j.14678624.2008.01189.x

Pelton, J., Gound, M., Forehand, R., \& Brody, G. (2004). The Moral Disengagement Scale: Extension with an American Minority Sample. Journal of Psychopathology and Behavioral Assessment, 26(1), 31-39. https://doi.org/10.1023/B:JOBA.0000007454.34707.a5

Perren, S., Gutzwiller-Helfenfinger, E., Malti, T., \& Hymel, S. (2012). Moral reasoning and emotion attributions of adolescent bullies, victims, and bully-victims. British Journal of Developmental Psychology, 30(4), 511-530. https://doi.org/10.1111/j.2044835X.2011.02059.X

Peterson, C., \& Seligman, M. E. P. (2004). Character Strengths and Virtues: A Handbook and Classification. Retrieved from Google Scholar

Pornari, C. D., \& Wood, J. (2010). Peer and cyber aggression in secondary school students: The role of moral disengagement, hostile attribution bias, and outcome expectancies. Aggressive Behavior, 36(2), 81-94. https://doi.org/10.1002/ab.20336

Ramdani, Z. (2018). Construction of academic integrity scale. International Journal of Research Studies in Psychology, 7(1). https://doi.org/10.5861/ijrsp.2018.3003

Robson, C., \& Witenberg, R. T. (2013). The Influence of Moral Disengagement, Morally Based Self-Esteem, Age, and Gender on Traditional Bullying and Cyberbullying. Journal of School Violence, 12(2), 211-231. https://doi.org/10.1080/15388220.2012.762921

White-Ajmani, M. L., \& Bursik, K. (2014). Situational context moderates the relationship between moral disengagement and aggression. Psychology of Violence, 4(1), 90-100. https://doi.org/10.1037/a0031728

Wray-Lake, L., \& Syvertsen, A. K. (2011). The developmental roots of social responsibility in childhood and adolescence. New Directions for Child and Adolescent Development, 2011(134), 11-25. https://doi.org/10.1002/cd.308

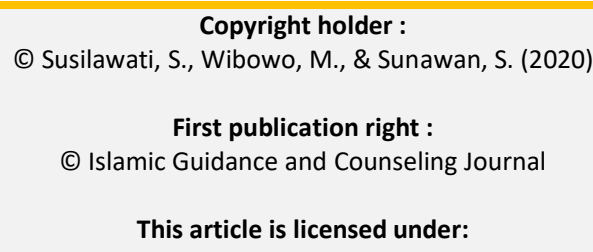

